\title{
Supplementary Material for \\ FALL3D-8.0: a computational model for atmospheric transport and deposition of particles, aerosols and radionuclides - Part 2: model applications
}

\author{
Andrew T. Prata ${ }^{1}$, Leonardo Mingari ${ }^{1}$, Arnau Folch $^{1}$, Giovanni Macedonio ${ }^{2}$, and Antonio Costa ${ }^{3}$ \\ ${ }^{1}$ CASE Department, Barcelona Supercomputing Center, Barcelona, Spain \\ ${ }^{2}$ Istituto Nazionale di Geofisica e Vulcanologia, Osservatorio Vesuviano, Napoli, Italy \\ ${ }^{3}$ Istituto Nazionale di Geofisica e Vulcanologia, Sezione di Bologna, Bologna, Italy \\ Correspondence: Andrew Prata (andrew.prata@bsc.es)
}

\section{S1 Video animations}

Six video animations have been uploaded to the TIB AV-Portal (https://av.tib.eu/). Titles of the videos and DOIs are listed below:

1. FALL3D-8.0 volcanic ash data insertion simulations for the 2011 Puyehue-Cordón Caulle (Chile) eruption (https://doi.org/10.5446/47095)

2. FALL3D-8.0 volcanic SO2 data insertion simulations for the 2019 Raikoke (Russia) eruption (https://doi.org/10.5446/47096)

3. FALL3D-8.0 volcanic ash simulations for the 2013 Mt Etna (Italy) eruption (https://doi.org/10.5446/47097)

4. FALL3D-8.0 Cs-134 radionuclide simulations for the 1986 Chernobyl (Ukraine) nuclear accident (https://doi.org/10.5446/47098)

5. FALL3D-8.0 Cs-137 radionuclide simulations for the 1986 Chernobyl (Ukraine) nuclear accident (https://doi.org/10.5446/47099)

6. FALL3D-8.0 I-131 radionuclide simulations for the 1986 Chernobyl (Ukraine) nuclear accident (https://doi.org/10.5446/47100) 